\title{
IEDITORIAL
}

\section{Cardiac monitoring: is longer better?}

\author{
Leonardo Liberman, Nicole Liberman, Eric S. Silver
}

Division of Pediatric Cardiology, Department of Pediatrics, Vagelos College of Physicians and Surgeons, Columbia University, New York, United States

\section{RELATED ARTICLE}

by Bieganowska

et al, see p. 129
Correspondence to: Leonardo Liberman, MD, Division of Pediatric Cardiology, Department of Pediatrics, Vagelos College of Physicians and Surgeons, Columbia University, 3959 Broadway Ave - 2 North, NY 10031, New York, United States, phone: +12123420525 email: I1202@cumc.columbia.edu Received: January 11, 2021. Accepted: January 12, 2021. Published online: February 25, 2021. Kardiol Pol. 2021; 79 (2): 110-111 doi:10.33963/KP.15825 Copyright by the Author(s), 2021
Since the original description of the first mobile cardiac monitoring device by Norman J. Holter, ${ }^{1}$ the technology has improved significantly. The previously heavy equipment has evolved into miniaturized devices that can be carried in a patient's pocket or worn on a wrist continuously. The classic Holter recorded the data on a tape until about 20 years ago when digital recording improved the technology. The Holter monitor has several benefits in arrhythmia monitoring and diagnosis including arrhythmia counts, measurement of heart rate variability, QT interval measurement, ST-segment analysis, and analysis of pacemaker function, among others. However, the traditional Holter monitor is limited by its duration of 24 or 48 hours and the rhythm abnormalities cannot be identified until the return and analysis of the recorded data. In the last 2 decades, multiple monitors have been designed to improve the traditional Holter. First, nonlooping cardiac monitors were used for recording of arrhythmias during symptom occurrence and the data were transmitted using a telephone landline. Then, looping cardiac monitors enabling automatic detection of arrhythmias were designed and, more recently, ambulatory cardiac telemetry has been used to record the information and transmit it to a monitoring center in "real time" using wireless telephone technology. The evolving technology has different presentations and indications that have been summarized in an expert consensus statement. ${ }^{2}$

There have been hundreds of studies comparing the "gold standard" Holter monitor with many of the new monitors. We have recently compared the results of Holter monitors with a patch monitor technology in the detection of arrhythmias in children who wore both devices simultaneously. ${ }^{3}$ Our findings suggested that some of the new monitors used are as good as the classic Holter monitor in detecting arrhythmias in symptomatic as well as in asymptomatic patients, but they can be worn for longer periods of time.

In the current issue of Kardiologia Polska (Kardiol Pol, Polish Heart Journal), Bieganowska et $\mathrm{al}^{4}$ provide us with another comparison. This time, in a multicenter study including 13 pediatric cardiology centers in Poland, the researchers compared the yield of long-term telemetric electrocardiogram monitoring with the standard 24-hour Holter monitoring for the diagnosis of rhythm abnormalities in children with palpitations. The 2 groups were similar in terms of demographic characteristics, duration of symptoms, cardiac diagnosis, and electrocardiographic findings. It is not surprising that the number of patients who reported palpitations during the monitoring period was higher in the telemetry group, as the monitoring time was longer. Similarly, the cause of palpitations was established in $44 \%$ of the patients in the telemetry group versus $12 \%$ after two 24-hour Holters had been performed.

Although the report has some methodological flaws and, as the authors stated, those findings were "intuitively" expected, because the patients in the telemetry group were monitored for a longer period of time, the study gives us some important lessons. All rhythm abnormalities, including supraventricular and ventricular tachycardia, conduction abnormalities, ectopy, and bradycardia were found in a greater number of patients during prolonged monitoring with telemetry, which indicated that only 24-hour Holter monitoring might not be sufficient to detect these rhythm abnormalities. This concept has been recently illustrated in adult patients with premature ventricular contractions (PVCs) who underwent 14-day ambulatory cardiac monitoring. There was a significant variation in the daily PVC burden, indicating that 24-hour monitoring might be misleading in determining the representative PVC count in a patient. ${ }^{5}$ 
The technology for noninvasive cardiac monitoring has significantly evolved over the last 2 decades, with smaller and smarter devices using cellular technology that enable us to interpret data in real time. Now, we even have implantable cardiac monitors that are small and easy to implant and can be continuously followed remotely. One cannot stop wondering, what is in the future? However, one thing is certain: monitoring for longer time will give the provider more information and more arrhythmias will likely be detected. Whether we want to know that information is a subject of a different debate.

\section{ARTICLE INFORMATION}

DISCLAIMER The opinions expressed by the author(s) are not necessarily those of the journal editors, Polish Cardiac Society, or publisher.

CONFLICT OF INTEREST None declared.

OPEN ACCESS This is an Open Access article distributed under the terms of the Creative Commons Attribution-NonCommercial-NoDerivatives 4.0 International License (CC BY-NC-ND 4.0), allowing third parties to download articles and share them with others, provided the original work is properly cited, not changed in any way, distributed under the same license, and used for noncommercial purposes only. For commercial use, please contact the journal office at kardiologiapolska@ptkardio.pl.

HOW TO CITE Liberman L, Liberman N, Silver ES. Cardiac monitoring: is longer better? Kardiol Pol. 2021; 79: 110-111. doi:10.33963/KP.15825

\section{REFERENCES}

1 Holter NJ. New method for heart studies. Continuous electrocardiography of active subjects over long periods is now practical. Science. 1961; 134: 1214-1220.

2 Steinberg JS, Varma N, Cygankiewicz I, et al. 2017 ISHNE-HRS expert consensus statement on ambulatory ECG and external cardiac monitoring/telemetry. Heart Rhythm. 2017; 14: e55-e96.

3 Bolourchi M, Silver ES, Muwanga D, et al. Comparison of Holter with Zio Patch electrocardiography monitoring in children. Am J Cardiol. 2020; 125: 767-771.

4 Bieganowska K, Miszczak-Knecht M, Brzezińska M, et al. Usefulness of long-term telemetric electrocardiogram monitoring in the diagnosis of tachycardia in children with a medical history of palpitations. Kardiol Pol. 2021; 79: 129-138.

5 Mullis AH, Ayoub K, Shah J, et al. Fluctuations in premature ventricular contraction burden can affect medical assessment and management. Heart Rhythm. 2019; 16: 1570-1574. 